\title{
Typologia sal o układzie centralnym tarasowym
}

\author{
Joanna Jabłońska \\ e-mail: joanna.jablonska@pwr.edu.pl
}

Katedra Architektury Użyteczności Publicznej i Podstaw Projektowania, Wydziat Architektury Politechniki Wroctawskiej

\begin{abstract}
Streszczenie: Współczesne sale koncertowe z widowniami powyżej 1800 osób, prezentują szereg innowacyjnych rozwiązań przestrzennych. Mimo niewątpliwej różnorodności rzutów, większość z nich bazuje na planie Filharmonii w Berlinie, którą otwarto w 1963 r. W związku z zaobserwowanymi podobieństwami i różnicami w omawianych wnętrzach, powstających na przestrzeni lat 70. XX w., po początek lat 2000, w niniejszym opracowaniu zaprezentowano autorską typologię sal koncertowych o tzw. układzie centralnym z tarasami.
\end{abstract}

Słowa kluczowe: akustyka architektoniczna, architektura sal koncertowych, konfiguracja centralna z tarasami, sale koncertowe, sale widowiskowe, winnice

\section{Wstęp}

W II p. XX w. powstała nowatorska konfiguracja sali koncertowej, która akustykom i architektom umówiła projektowanie przestrzeni o doskonałych parametrach akustycznych, przeznaczonych dla pojemności widowni powyżej 1800 osób. Tym innowacyjnym rozwiązaniem była, otwarta w 1963 r. Berliner Philharmonie (oryginalna nazwa niemiecka, dalej w tekście spolszczona, jako Filharmonia w Berlinie), wzniesiona wg projektu architekta Hansa Scharouna, przy współpracy akustyka Lothara Cremera. [Jabłońska 2008], [Wisniewski, 1993]

Stąd na 1963 r. datuje się istotny przełom w projektowaniu współczesnych wnętrz sal koncertowych, wprowadzający do kanonu akustyki architektonicznej, tzw. układ centralny z tarasami (definicja poniżej). Fakt ten zbiegł się z rozpoczęciem intensywnych badań nad dźwiękiem - m.in.: Leo Beraneka (prowadzone w latach 60. XX w.), Richarda Bolta (w latach 60. XX w.), Roberta Newmana (w latach 60. XX w.), Rusella Johnsona (w latach 70. XX w.), Harolda Marshalla (w latach 70. XX w.) - co pośrednio przyczyniło się do rozwoju tego układu. [Barron 1993], [Beranek 1996] Następnie, kluczowe znaczenie w tym procesie miało też zastosowanie technologii komputerowej, pozwalające na przewidywanie właściwości i parametrów akustycznych projektowanych sal koncertowych, a dynamiczna ewolucja układu centralnego tarasowego trwa do dziś. [Schmolke 2011]

\section{Definicja}

Termin układ centralny tarasowy zaczerpnięty został z literatury anglojęzycznej i stanowi parafrazę określenia tarasy winnicy (ang. vineyard terraces). W źródłach [Barron 1993], [Beranek 1996], [Shield, Cox 1999/2000] pojęcie odwołuje się bezpośrednio do sposobu budowy sali koncertowej, w której widownia przypomina swym układem tradycyjną uprawę winogron na zboczach pagórków. W literaturze możemy spotkać wymienne stosowanie określeń: tarasy winnicy, winnica (ang. vineyard) lub konfiguracja winnicy. Ze względu na brak odpowiedniego terminu w języku polskim przyjęto nazwę układ centralny tarasowy. [Kulowski 2007], [O'Keefe 1998], [Marshall, Barron 2001], [Shield, Cox 1999/2000] 
Układem centralnym tarasowym - nazywano wnętrze sali koncertowej ze sceną położoną w środku (środek: geometryczny, czasem położenie asymetryczne), otoczoną ze wszystkich stron widownią. Rzędy siedzisk widowni, wznoszą się zgodnie z wykresem dobrej widoczności, ale dodatkowo są pogrupowane i umieszczone na tarasach, które wypiętrzają się w kierunku korony sali. Powstałe między tarasami ściany - pełne fronty tarasów - stanowią dodatkowe płaszczyzny służące do: zróżnicowania kierunków odbicia fal akustycznych, zapewnienia dobrego zmieszania dźwięku bezpośredniego z dźwiękiem z pierwszego odbicia bocznego i zapewnienia powstawania intensywnych kolejnych odbić dźwięku. W efekcie w salach o konfiguracji winnicy możliwe jest zgromadzenie większej liczby słuchaczy niż w innych rodzajach sal, ze względu na: zbliżenie wszystkich słuchaczy do źródła dźwięku (sceny), zapewnienie bocznych odbić fali dźwięku o wysokiej energii akustycznej (dodatkowe ściany tarasów) i zapewnienie wysokiej jakości, równomiernego pola akustycznego na całej powierzchni wnętrza (geometria rzutu). [Kulowski 2007], [O'Keefe 1998], [Shield, Cox 1999/2000]

\section{Systematyka}

Od lat 70. XX w. do współczesności z omawianej konfiguracji korzystali różni projektanci i akustycy, a co więcej była ona wykorzystywana na obszarach odmiennych kulturowo. Jak wspomniano rozpoczęto też używanie komputerowych narzędzi wspomagających projektowanie, które pozwoliło na planowanie coraz bardziej złożonych układów przestrzennych o dobrej akustyce. Stąd w grupie sal o układzie centralnym tarasowym, powstał szereg zróżnicowanych układów przestrzennych, które zaszeregowano poniżej. Na podstawie analizy kształtu rzutów i przekrojów wybranych około 24 sal o konfiguracji centralne z tarasami (analizy w odrębnym opracowaniu), zostały wyodrębnione 3 typy wnętrz: semi-centralny, arenowy i hybrydowy (Ryc. 1).

Sale należące do układu centralnego tarasowego - (układ winnicowy) (rys. 1) charakteryzuje rzut oparty na figurze zbliżonej do okręgu (okrąg, elipsa i wielokąt) o podobnych wartościach szerokości i długości. Kolejną cechą jest centralne położenie sceny, nie zawsze w środku geometrycznym wnętrza. Praktycznie całość widowni lokalizuje się na tarasach, wypiętrzonych w kierunku korony. Przewyższenie poszczególnych rzędów jest znaczne i zapewniające korzystne linie widoczności, a tym samym dobrą słyszalność. Rzuty i przekroje sceny, ścian i tarasów projektowane są jako prostokreślne, na łukach lub krzywych Béziera. Nad sceną zawieszany jest ustrój z paneli odbijających i rozpraszających dźwięk w kierunkach sceny i widowni. Sala w typie podstawowym najczęściej przekrywana jest sufitem namiotowym, którego wypukłe pola są kierowane w stronę wnętrza.

Przykładami sal o układzie centralnym z tarasami są: sala główna Filharmonii Berlińskiej (1963) i Nezahualcoyotl w Nowym Meksyku (1978).

Typ semi-centralny (pół-centralny) - obejmuje sale (rys. 1) o rzutach zakładanych na formach eliptycznych lub wielobocznych. Wartości szerokości i długości sal pozostają w podobnej relacji, jak w układzie podstawowym. Scena zlokalizowana jest najczęściej w sąsiedztwie tylnej ściany sali, a za sceną sytuowane są jedynie miejsca dla chóru. Wyjątkowo, gdy chór nie jest obecny, w trakcie przedstawienia, jego miejsca mogą być udostępniane publiczności. Widownia w typie semi-centralnym podzielona jest na trzy części: widownię frontową, której nadawany jest kształt klasyczny, i dwie widownie boczne, sytuowane na tarasach. Dla tego typu wnętrza nie występuje żaden charakterystyczny rodzaj stropu.

Wśród przykładów wnętrz w typie semi-centralnym układu centralnego tarasowego można wymienić: Roy Tompson Hall (1972), Christchurch Town Hall (1972) i Michael Fowler Centre (1983).

Typ arenowy - występuje w obrębie sal o konfiguracji winnicowej (Ryc. 1). Jest to jedyny typ charakteryzujący się pełną centralnością, w którym scena położona jest w geometrycznym środku wnętrza i otoczona symetryczną widownią. Symetria widowni wyprowadzona jest według trzech, częściej czterech osi, ale od tej zasady odnotowano odstępstwa (np.: spiralne wnętrze MuZa w Kawasaki). Całość widowni sytuowana jest na tarasach o rzutach wielobocznych, prostokreślnych, których fronty stanowią nieodzowne, przy braku klasycznych ścian bocznych, płaszczyzny odbijające. Sale przekrywa się zwykle sufitem namiotowym, a w związku z tym maksymalną wartość wysokości wnętrze osiąga nad sceną, co wiąże się z koniecznością zawieszania w tym miejscu układów paneli akustycznych - odbijających i rozpraszających dźwięk. Przestrzeń znajdująca się nad tymi panelami służy jako komora rewerberacyjna.

Wśród przykładów sal centralnych, tarasowych w typie arenowym można wymienić: salę kameralną Filharmonii w Berlinie (1987), Music Centre Vredenburg w Utrechcie (1979) i MuZa w Kawasaki (2004). 
Typ hybrydowy - obejmuje rozwiązania, w których połączono najkorzystniejsze cechy typu podstawowego układu centralnego tarasowego, z cechami występującymi w innych konfiguracjach wnętrz przeznaczonych do słuchania muzyki, np.: konfiguracji pudełkowej czy wachlarzowej (rys. 1). Rzut typu hybrydowego jest zwykle dłuższy od typu podstawowego, a szerokość wyraźnie zredukowana. Zmodyfikowane są również proporcje poszczególnych widowni, kolejno: największa jest widownia frontowa, mniejsze - przeważnie symetryczne są widownie boczne, a najmniejsza jest widownia tylna. Przednia część widowni frontowej, zaaranżowana jest w sposób klasyczny, z odpowiednim przewyższeniem kolejnych rzędów wynikającym z wykresu dobrej widoczności. Tylna część widowni frontowej lokalizowana jest na jednym, dwóch lub trzech tarasów, podobnie jak widownie boczne i tylna - w zależności od zaprojektowanej liczby miejsc. Tarasy są łagodnie wypiętrzane ku koronie widowni, a w związku z ich zmniejszoną liczbą w stosunku do typu podstawowego - wnętrze przyjmuje układ horyzontalny. W układach hybrydowych najczęściej stosowane są sufity baldachimowe oraz dodatkowe ustroje wiszące nad sceną, pełniące takie same funkcje jak ustroje stosowane we wcześniejszych typach. Sale o takim rozwiązaniu są wybierane najczęściej we współczesnym projektowaniu.

Przykładowe projekty tego typu wnętrz to: Suntory Hall Tokyo (1986), Sapporo Concert Hall "Kitara” (1997), Ryutopia Niigata City Performing Arts Cente (1998), Walt Disney Hall (2003), Atlanta Symphony Center (2012).

Początkowo, wszystkie sale centralne tarasowe rozwiązywano na rzutach ukształtowanych z prostych odcinków - najczęściej zestawianych w formie figur wielobocznych, nieforemnych. W 1978 roku w Boettcher Concert Hall po raz pierwszy wprowadzono łuki w projektowaniu rzutu, a w 1997 roku zaprojektowano salę Sapporo Concert Hall, w której łuki zastąpiono krzywymi Bézier'a. Takie rozwiązania upowszechniły się i są stosowane w większości nowo wznoszonych sal centralnych tarasowych. W związku z tymi transformacjami, można wyróżnić następujące typy rzutów winnicowych, wyróżnianych ze względu na krzywiznę ścian: prostokreślne lub z łukami (rys. 2).

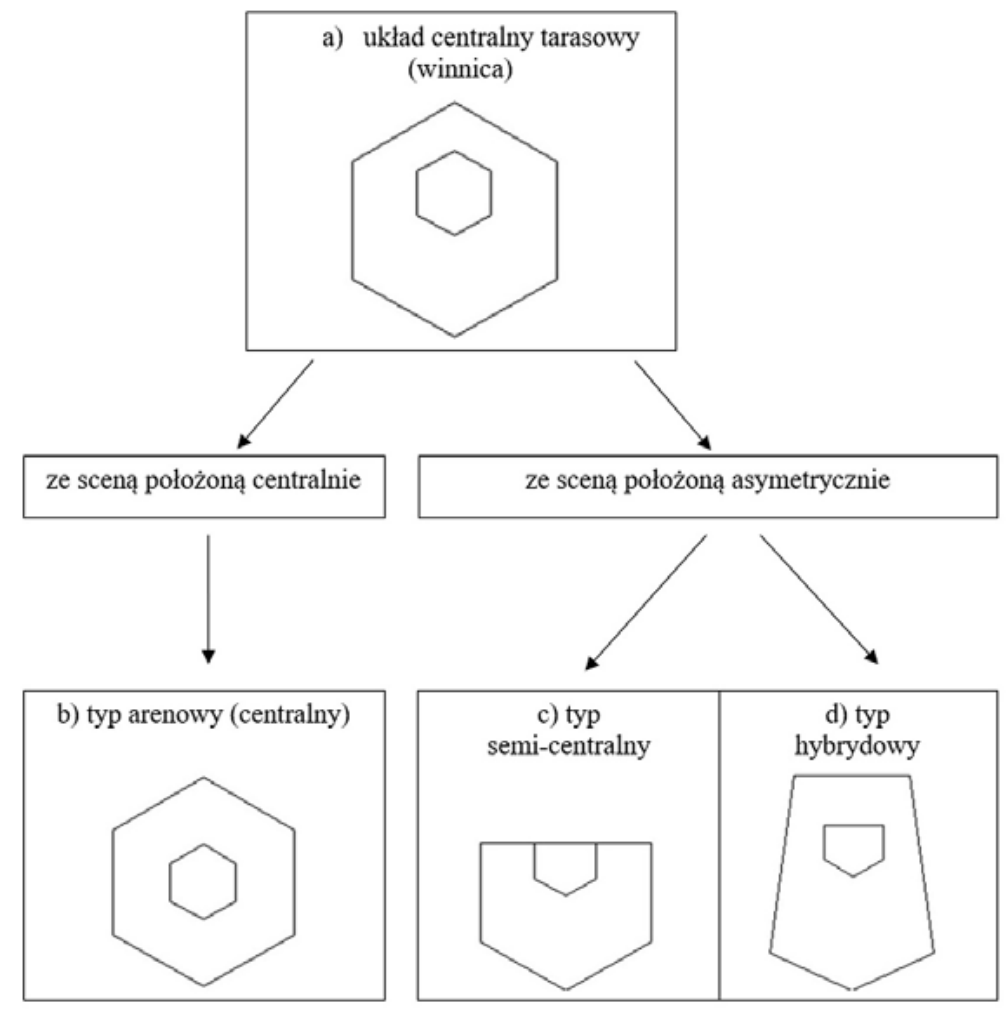

Ryc. 1. Podział układów centralnych tarasowych ze względu na kształt wnętrza: a) układ centralny tarasowy, typy: b) arenowy (centralny), c) semi-centralny, d) hybrydowy [oprac. autorki] 


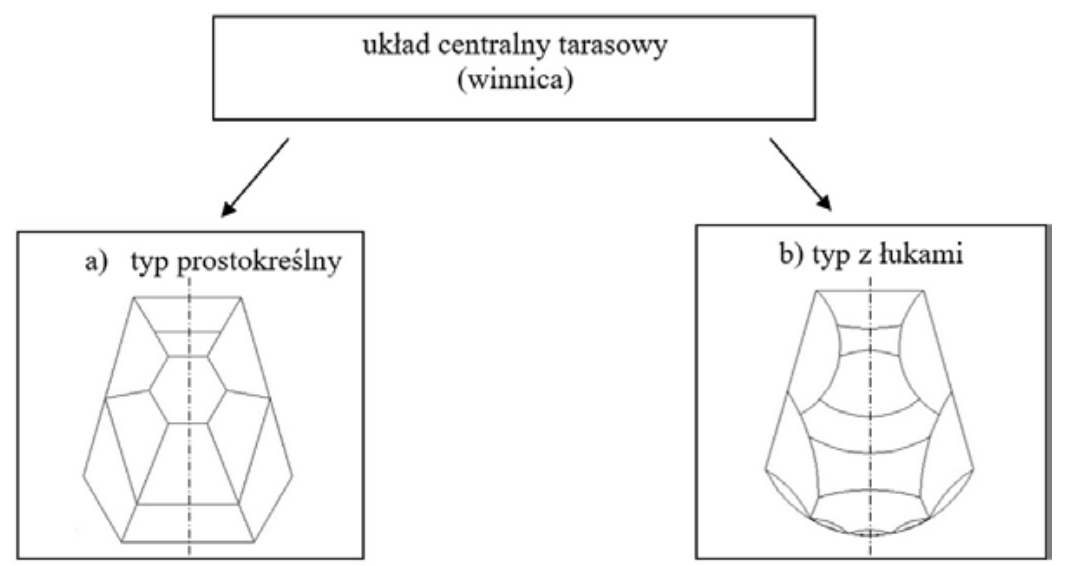

Ryc. 2. Typ I układu centralnego tarasowego - ze względu podłużną oś symetrii, typ: a) prostokreślny, b) z łukami [oprac. autorki]

Można też wyróżnić, ze względu na symetrię układów - rozwiązania symetryczne i asymetryczne (rys. 3). Najczęściej spotyka się symetrię podłużną - według osi środkowej. W analizowanych typach arenowych, opisano symetrię według trzech i czterech osi. Sala Filharmonii w Berlinie zapoczątkowała nurt winnic, w układzie asymetrycznym, choć rzut tego obiektu wykazuje asymetrię jedynie względem niewielkich fragmentów wnętrza, np.: górnej loży bocznej. Kolejnym rozwiązaniem tego typu jest sala Boettcher, a wśród najnowszych realizacji sala - Muza w Kawasaki.

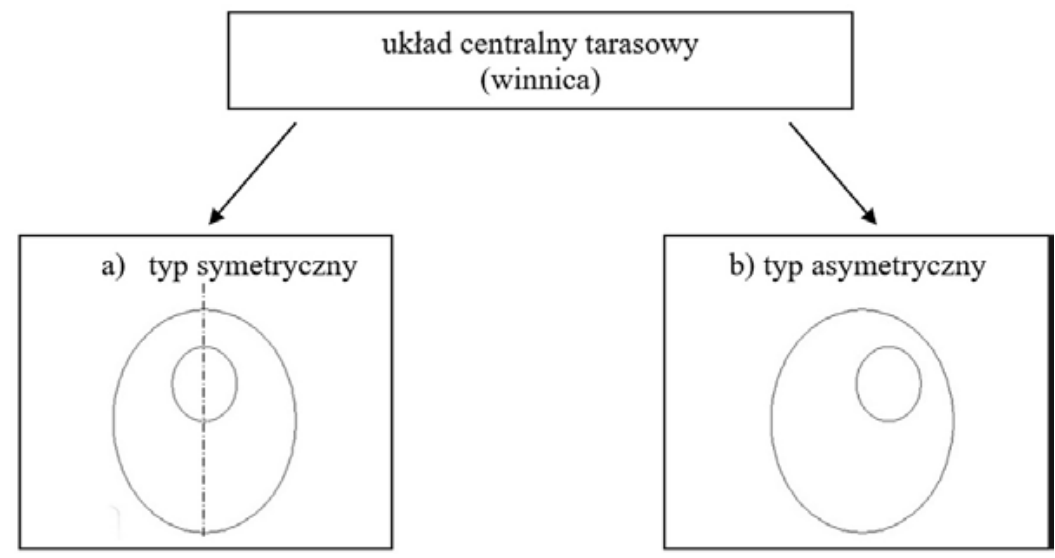

Ryc. 3. Typ II układów centralnych tarasowych - ze względu na symetrię rozplanowania, typ: a) symetryczny, b) asymetryczny [oprac. autorki]

\section{Podsumowanie}

Podsumowanie i chronologiczne usystematyzowanie sal koncertowych o konfiguracji centralnej z tarasami, zostało zaprezentowane w poniższej tabeli z zastosowaniem opracowanej typologii. Tabela zawiera: linię czasu, nazwy, schematy rzutów i typy sal. Zaproponowane schematy rzutów sal koncertowych odzwierciedlają w sposób uproszczony rzeczywiste plany. 
Tabela 1. Zmiany cech sal centralnych tarasowych w latach 60. I 70. XX w. [oprac. autorki].

\begin{tabular}{|c|c|c|c|c|c|c|c|c|c|c|c|}
\hline & \multirow[b]{2}{*}{ Data } & \multirow[b]{2}{*}{ Nazwa obiektu } & \multirow[b]{2}{*}{$\begin{array}{c}\text { Schemat wnęt- } \\
\text { rza }\end{array}$} & \multicolumn{4}{|c|}{$\begin{array}{l}\text { Układ centralny ta- } \\
\text { rasowy }\end{array}$} & \multicolumn{2}{|c|}{ Typ I } & \multicolumn{2}{|c|}{ Typ II } \\
\hline & & & & 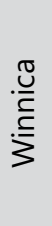 & 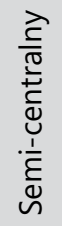 & $\begin{array}{l}\sum_{0} \\
\frac{C}{d} \\
\frac{c}{4}\end{array}$ & \begin{tabular}{l} 
\} $\\
{\frac{0}{0}} \\
{\frac{\lambda}{2}} \\
{\frac{0}{\lambda}}$ & 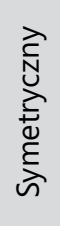 & 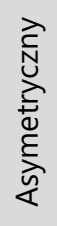 & 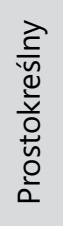 & $\frac{\overline{\frac{E}{\sigma}}}{\frac{\bar{v}}{\vec{T}}}$ \\
\hline 1 & 1963 & $\begin{array}{c}\text { Berliner Philhar- } \\
\text { monie } \\
\text { w Berlinie }\end{array}$ & & + & & & & & + & + & \\
\hline 2 & 1972 & $\begin{array}{l}\text { Roy Thomson Hall } \\
\text { w Toronto }\end{array}$ & & & + & & & + & & + & \\
\hline 3 & 1972 & $\begin{array}{c}\text { Christchurch Town } \\
\text { Hall } \\
\text { w Christchurch }\end{array}$ & & & + & & & + & & + & \\
\hline
\end{tabular}
\end{tabular}

Tabela 2. Zmiany cech sal centralnych tarasowych w latach 80. XX w. [oprac. autorki].

\begin{tabular}{|c|c|c|c|c|c|c|c|c|c|c|c|}
\hline & \multirow[b]{2}{*}{ Data } & \multirow[b]{2}{*}{ Nazwa obiektu } & \multirow[b]{2}{*}{$\begin{array}{l}\text { Schemat wnęt- } \\
\text { rza }\end{array}$} & \multicolumn{4}{|c|}{$\begin{array}{l}\text { Układ centralny ta- } \\
\text { rasowy }\end{array}$} & \multicolumn{2}{|c|}{ Typ I } & \multicolumn{2}{|c|}{ Typ II } \\
\hline & & & & 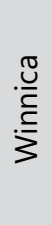 & 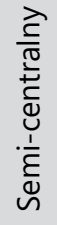 & 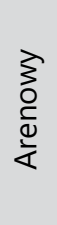 & $\begin{array}{l}\frac{\lambda}{0} \\
\frac{0}{0} \\
\frac{\lambda}{2} \\
\frac{1}{1}\end{array}$ & 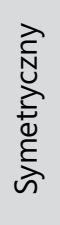 & 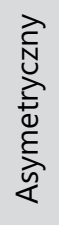 & 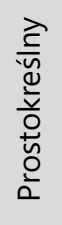 & $\begin{array}{l}\overline{\frac{E}{D}} \\
\frac{\bar{D}}{\vec{T}} \\
\text { N }\end{array}$ \\
\hline 9 & 1982 & $\begin{array}{l}\text { St. David's Hall } \\
\text { w Cardiff }\end{array}$ & & & & & + & + & & + & \\
\hline 10 & 1983 & $\begin{array}{c}\text { Michael Fowler } \\
\text { Centre } \\
\text { w Wellington }\end{array}$ & & & + & & & + & & + & \\
\hline
\end{tabular}




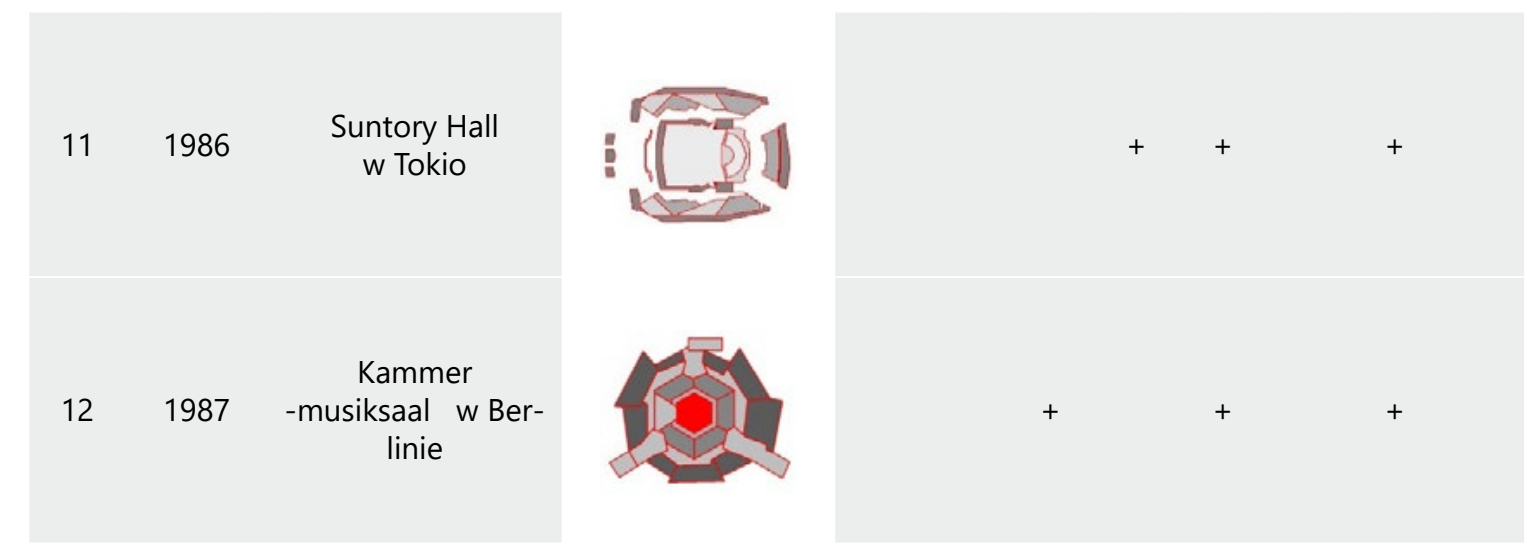

Tabela 3. Zmiany cech sal centralnych tarasowych w latach 90. XX w. [oprac. autorki].

\begin{tabular}{|c|c|c|c|c|c|c|c|c|c|c|c|}
\hline & \multirow[b]{2}{*}{ Data } & \multirow[b]{2}{*}{ Nazwa obiektu } & \multirow[b]{2}{*}{$\begin{array}{c}\text { Schemat wnęt- } \\
\text { rza }\end{array}$} & \multicolumn{4}{|c|}{$\begin{array}{c}\text { Układ centralny ta- } \\
\text { rasowy }\end{array}$} & \multicolumn{2}{|c|}{ Typ I } & \multicolumn{2}{|c|}{ Typ II } \\
\hline & & & & 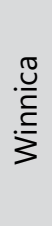 & 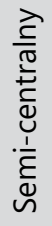 & $\begin{array}{l}\sum_{0}^{\lambda} \\
\frac{c}{d} \\
\frac{1}{4}\end{array}$ & $\begin{array}{l}\frac{3}{0} \\
\frac{\lambda}{2} \\
\frac{\lambda}{\lambda}\end{array}$ & 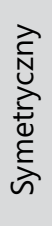 & 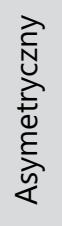 & 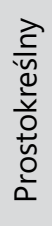 & $\frac{\frac{\bar{\varepsilon}}{\sqrt{2}}}{\frac{P}{N}}$ \\
\hline 13 & 1990 & $\begin{array}{c}\text { Glasgow Royal } \\
\text { Concert Hall } \\
\text { w Glasgow }\end{array}$ & & & & & + & + & & + & \\
\hline 14 & 1997 & $\begin{array}{c}\text { Sapporo Concert } \\
\text { Hall „Kitara” } \\
\text { w Sapporo }\end{array}$ & & & & & + & + & & & + \\
\hline 15 & 1998 & $\begin{array}{c}\text { Niigata City Perfor- } \\
\text { ming Arts Center } \\
\text { „Ryutopia” } \\
\text { w Niigata }\end{array}$ & & & & & + & + & & & + \\
\hline
\end{tabular}


Tabela 4. Zmiany cech sal centralnych tarasowych po roku 2000. [oprac. autorki].

\begin{tabular}{|c|c|c|c|c|c|c|c|c|c|c|}
\hline & \multirow[b]{2}{*}{ Data } & \multirow[b]{2}{*}{ Nazwa obiektu } & \multirow[b]{2}{*}{$\begin{array}{c}\text { Schemat wnęt- } \\
\text { rza }\end{array}$} & \multicolumn{3}{|c|}{$\begin{array}{l}\text { Układ centralny ta- } \\
\text { rasowy }\end{array}$} & \multicolumn{2}{|c|}{ Typ I } & \multicolumn{2}{|c|}{ Typ II } \\
\hline & & & & 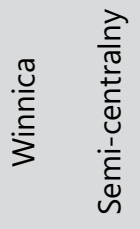 & 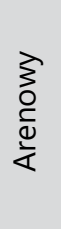 & 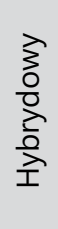 & 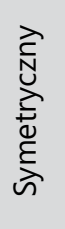 & 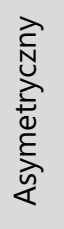 & 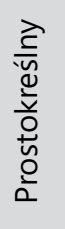 & $\begin{array}{l}\overline{\frac{\varepsilon}{0}} \\
\frac{\sqrt{v}}{\vec{P}} \\
\frac{N}{N}\end{array}$ \\
\hline 16 & 2003 & $\begin{array}{l}\text { Walt Disney Hall } \\
\text { w Los Angeles }\end{array}$ & & & & + & + & & & + \\
\hline 17 & 2004 & $\begin{array}{c}\text { Muza } \\
\text { w Kawasaki }\end{array}$ & & & + & & & + & + & \\
\hline 18 & 2005 & $\begin{array}{c}\text { Oriental Arts Cen- } \\
\text { ter } \\
\text { w Szanghaju }\end{array}$ & & & & + & + & & & + \\
\hline 19 & 2009 & $\begin{array}{l}\text { DR Koncerthuset } \\
\text { w Kopenhadze }\end{array}$ & & + & & & & + & + & \\
\hline
\end{tabular}

Sformułowana typologia ma istotne znaczenie w przedstawieniu zagadnień związanych z akustyką i jej korelacją z architekturą. Umożliwia w dalszym toku opracowań zobrazowanie wpływu poszczególnych rozwiązań przestrzennych wnętrz koncertowych na mierzalne parametry i subiektywny odbiór dźwięku, a także pozwala na jednoznaczne stosowanie terminologii. Jest to szczególnie istotne w przypadku rozwiązań współczesnych, stale przeobrażanych i udoskonalanych, a mających na celu zapewnienie optymalnych warunków do słuchania i wykonywania muzyki na żywo dla znacznej liczby osób - dla widowni powyżej 1800 miejsc.

\section{Piśmiennictwo}

[1] Barron M., 1993: Auditorium Acoustics and Architectural Design. London

[2] Beranek L., 1996: Concert and Opera House. How they sound. Acoustical Society of America. b.m.

[3] Jabłońska J., 2008: Nowatorska centralna sala tarasowa Filharmonii w Berlinie. Architectus. 1(23). 81-91

[4] Kulowski A., 2007: Akustyka sal. Wydawnictwo Politechniki Gdańskiej. Gdańsk

[5] Marshall A. H., Barron M., 2001: Spatial responsiveness in concert halls and the origins of spatial impression. Applied Acoustics. 62 (2). 91-108

[6] Wisniewski E., 1993: Die Berliner Philharmonie und Ihr Kammermusiksaal. Der Konzertsaal als Zentralraum. Gebr. Mann Verlag. Berlin

[7] O'Keefe J., 1998: The New Understanding of Acoustics. Spatial Impression. http://www.zainea.com/The_New_Understanding_of_Acoustics.htm

[8] Schmolke B., 2011: Theatres and Concert Halls. Construction and Design Manual. DOM Publishers. b. m.

[9] Shield B., Cox T. 1999/2000: The Shape We're In. The story of the Berlin Philharmonie - a landmark hall. www.acoustics. salford.ac.uk/acoustics_world/concert_hall_acoustics/shape.html 


\section{Typology of rooms with a central terrace system}

\section{Joanna Jabłońska}

e-mail: joanna.jablonska@pwr.edu.pl

Department of Public Use Building Architecture and Design Elements, Faculty of Architecture of Wroclaw University of Science and Technology

Summary in English: Contemporary concert halls with auditoriums over 1800 people, are representatives of a number of innovative spatial solutions. Despite, undutiful layouts variety, most of them origin in plan of Berlin Philharmonic Hall, which was opened in year 1963. Due to differences and similarities observed in elaborated interiors, erected from 70 . of XX cent., till beginning of years 2000 , in this elaboration there was presented original typology of, so called: vineyard concert halls.

Key words: architectural acoustics, architecture of concert halls, central configuration with terracess, concert halls, performance halls, vineyards 